\title{
Effects of Current Pacing and Electrical Field on The Turbulence Induced by Voltage Oscillations in Hearts
}

\author{
Hong Zhang* \\ School of Electrical Engineering \\ Xi'an Jiaotong University \\ Xi'an, China \\ *Corresponding author \\ Dan Zhao \\ School of Electrical Engineering \\ Xi'an Jiaotong University \\ Xi'an, China
}

\author{
Ruijuan Li \\ School of Electrical Engineering \\ Xi'an Jiaotong University \\ Xi'an, China \\ Yuan Liu \\ School of Electrical Engineering \\ Xi'an Jiaotong University \\ Xi'an, China
}

\begin{abstract}
To the turbulence induced by local voltage oscillations during repolarizing phase of the cardiac action potential, the effects of current pacing and electrical field were investigated to reveal their feasibilities in elimination of the turbulence. A local pathological 2-dimensional tissue including $401 \times 401$ myocytes was developed on the basis of LR91 single cell mathematical model. The myocytes at the central $20 \times 20$ region was characterized with voltage oscillations by increasing time constant of $\mathrm{K}^{+}$gating variable and maximum conductance of $\mathrm{Ca}^{2+}$ current. The cross field method was used to induce spiral waves that degraded to turbulence-like fibrillation under the influence of pathological region. The defibrillation model was created by introducing the current and electrical field terms, respectively. The computer simulation results showed that local current pacing had no significant effects on the turbulence, but after subsequent application of electrical field, the turbulence was depressed around $240 \mathrm{~ms}$. Current pacing on the whole tissue was able to completely suppress wave breakup at $625 \mathrm{~ms}$, but with the execution of electrical field, the elimination time reduced to $\mathbf{2 4 0}$ ms. Therefore, current pacing together with electrical field has greater effects on electrical activities of the tissue. It promotes the process to suppress the wave breakup, thus eliminating the turbulence-like fibrillation.
\end{abstract}

Keywords-turbulence; current pacing; electrical field; action potential mathematical model; computer simulations

\section{INTRODUCTION}

Cardiac tissue can be considered as a biological excitable media. Its electrical activities display spatio-temporal dynamics that can range from ordered to turbulent [1]. The electrical turbulence in hearts is known as fibrillation which may disrupt synchronous contraction of the cardiac muscle and lead to sudden death. Therefore, how to effectively control the turbulence on the tissue is being extensively studied [2,3].

High voltage electric shock is usually used for defibrillations. This method not only produces pain to the patient, but also may induce new fibrillations on the tissue [4]. Therefore, current research again focuses on optimizing serial defibrillation, delivering a temporal sequence of low-energy shocks that aim to develop a painless and damage-free solution to restoring a regular rhythm without losing efficacy [5].

It is known that complex oscillatory behaviors are common phenomena in excitable system. Cardiac myocytes can also exhibit pathological excitations that appear as voltage oscillations during the repolarizing phase of the action potential They have been implicated as a major cause of lethal cardiac arrhythmias such as fibrillation [6], but how to control the turbulence-like fibrillation induced by the voltage oscillations hasn't been extensively studied. Therefore, in the present paper, by developing a local pathological cardiac tissue model, the effects of current pacing and electrical field were investigated to reveal their possible applications in elimination of the turbulence.

\section{METHODS}

\section{A. Tissue Model and Numerical Intergation}

A cardiac tissue can be treated as a continuous system in which a two-dimensional sheet of isotropic ventricular muscle can be modeled by the reaction-diffusion equation (1) with the impermeable boundary condition (2) as follows [7]:

$$
\begin{aligned}
& \frac{\partial V}{\partial t}=\frac{1}{C_{m}}\left(-I_{i o n}\right)+D\left(\frac{\partial^{2} V}{\partial x^{2}}+\frac{\partial^{2} V}{\partial y^{2}}\right) \\
& \left.\frac{\partial V}{\partial x}\right|_{x=x_{\min }, x_{\max }}=\left.\frac{\partial V}{\partial y}\right|_{y=y_{\min }, y_{\max }}=0
\end{aligned}
$$

where $D$ is the diffusion coefficient for the membrane potential, $C_{\mathrm{m}}$ is the membrane capacitance, $I_{\text {ion }}$ is the total ionic current, $t$ is time, $x$ and $y$ are spatial coordinates in the sheet. $x_{\min }, x_{\max }$, $y_{\min }$ and $y_{\max }$ represent four edges of the two-dimensional tissue, respectively.

In the present paper, the tissue included $401 \times 401$ elements. Each one was described by a Luo-Rudy single cell model [8] that was electrically coupled with four immediate neighbors by gap junctions. Therefore, for the four borders $x_{\min }=0, x_{\max }=$ $400, y_{\min }=0, y_{\max }=400$. 
Because of the stiffness of (1), the operator splitting technique was used to accelerate the computation in which the ordinary differential equations describing the behavior of each single cell were solved separately from the partial differential equation describing the electrical diffusion [9]. In order to improve the accuracy, the alternating direction implicit method (ADI) was employed to integrate (1) in which the time step of $0.05 \mathrm{~ms}$ was used to keep all myocytes synchronized. The spatial step in $x$ and $y$ coordinate axis were $0.015 \mathrm{~cm}$.

\section{B. Oscillation Induction and Local Pathological Tissue}

Voltage oscillations during repolarization of the action potential were induced by properly matching time constants of $\mathrm{Ca}^{2+}$ gating variables $\tau_{d}, \tau_{f}$ and $\mathrm{K}^{+}$gating variables $\tau_{x}$.

The myocytes characterized with voltage oscillations were then arranged in the center of the developed two-dimensional slice as shown in FIGURE. 1A. The surroundings were the normal repolarizing myocytes. The centered region included $20 \times 20$ elements. Their action potentials are displayed in FIGURE. 1B. As noticed, multiple oscillations occurred during the plateau repolarizing phase of the action potential.



$(\mathrm{A})^{x}$

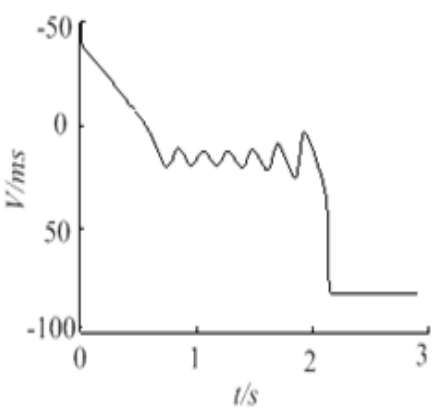

(B)
FIGURE I. SCHEMATIC DIAGRAM OF THE DEVELOPED LOCAL

PATHOLOGICAL TISSUE (A) AND THE ACTION POTENTIAL WITH VOLTAGE OSCILLATIONS (B)

\section{Delivery of External Forces}

The turbulence was induced on the developed local pathological tissue by the cross field method. After that, the effects of external forces on the turbulence were investigated. Firstly, the impact of current pacing was examined in which the periodic current with $30 \mu \mathrm{A} / \mathrm{cm} 2$ amplitude and $30 \mathrm{~ms}$ period was delivery to the tissue.

To investigate effects of the current pacing together with the electrical field, after one period of current pacing, a periodic electrical field was executed on the tissue. An additional term (3) was added to (1) to represent the electrical field:

$$
E_{\text {def }}=C_{\mathrm{m}} \varepsilon \frac{\partial V}{\partial x}
$$

where $\varepsilon$ was the coefficient of the electrical field strength.
The period of the delivered electrical field was $50 \mathrm{~ms}$ with pulse width of $10 \mathrm{~ms}$. Lax-Wandrof [11] method was used to integrate (3):

$$
\begin{array}{r}
\left.\varepsilon \frac{\partial V}{\partial x}\right|_{(l, n)}=-\frac{\varepsilon}{2 \Delta x}\left(V_{(l+1, n)}-V_{(l-1, n)}\right)+ \\
\frac{\varepsilon^{2} \Delta t}{2 \Delta x^{2}}\left(V_{(l+1, n)}-2 V_{(l, n)}+V_{(l-1, n)}\right)
\end{array}
$$

where $(1, n)$ was the coordinate of a myocyte on the tissue. $\Delta x$ was the space step along the $\mathrm{x}$ axis.

\section{RESUlTS AND DISCUSSION}

\section{A. Turbulence on the Developed Local Pathological Tissue}

FIGURE. 2 shows formation of the turbulence on the developed local pathological tissue. In the beginning, a plane wave was initiated by stimulus S1 at the top $401 \times 10$ zone. The excitation then propagated towards the bottom. When a gradient in refractoriness was established, the second stimulus S2 was applied to the left half zone of $200 \times 401$. Then as displayed in FIGURE. 2, at $170 \mathrm{~ms}$ because of recovery of the excitability at the right top area, the wave front curved and formed the head of the spiral wave. After several rotations, due to effects of the centered pathological region, the arm of the spiral wave close to the center started to break up at 620 $\mathrm{ms}$. Therefore, two separate waves were formed at $660 \mathrm{~ms}$. From then on, as shown at $700 \mathrm{~ms}, 780 \mathrm{~ms}$ and $1200 \mathrm{~ms}$, with annihilation of the original wave through collision of the wave front, several new waves were formed at the same time, resulting in turbulence pattern on the tissue. The breakup didn't stop until the end of the experiment at $2210 \mathrm{~ms}$.



$170 \mathrm{~ms}$

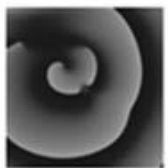

$660 \mathrm{~ms}$

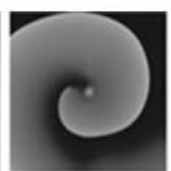

$360 \mathrm{~ms}$

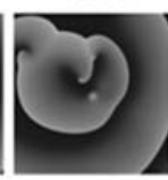

$700 \mathrm{~ms}$

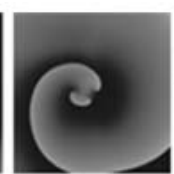

$400 \mathrm{~ms}$

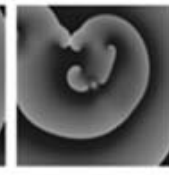

$780 \mathrm{~ms}$

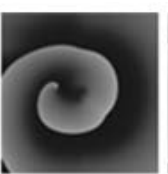

$430 \mathrm{~ms}$



$1200 \mathrm{~ms}$

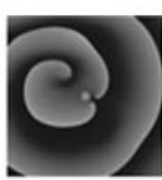

$620 \mathrm{~ms}$



$2210 \mathrm{~ms}$
$-90 \mathrm{mV}+40 \mathrm{mV}$

FIGURE II. ELECTRICAL WAVE PATTERNS ON THE DEVELOPED LOCAL PATHOLOGICAL TISSUE WHEN THE CROSS FIELD STIMULATION WAS APPLIED. THE TIME UNDER EACH PATTERN WAS RELATIVE TO THE TIME THAT S1 STIMULATION WAS STARTED TO DELIVER. THE GRAY SCALE BAR INDICATES RELATIONSHIP OF THE VOLTAGE AND THE GRAY COLOUR

\section{B. Effects of Current Pacing}

FIGURE. 3 exhibits wave patterns after the current pacing was delivered on a strip. At $0 \mathrm{~ms}$ the current was applied to the top region of $401 \times 50$ on the turbulence tissue. At $4 \mathrm{~ms}$, the membrane potential of the paced area was elevated, but the 
activated excitation failed to propagate from the top toward the bottom and finally disappeared. The results were the same for the following current pacings. Before the end of experiment at $628 \mathrm{~ms}$, the turbulence still sustained, indicating a very little influence of the local current pacing on electrical activities of the turbulence.

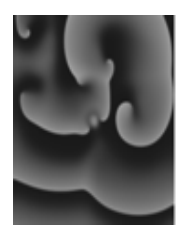

$0 \mathrm{~ms}$

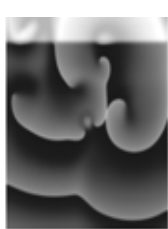

$4 \mathrm{~ms}$

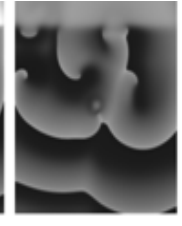

$16 \mathrm{~ms}$

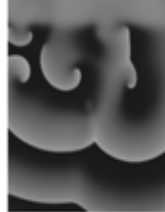

$28 \mathrm{~ms}$

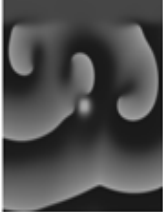

$628 \mathrm{~ms}$
FIGURE III. ELECTRICAL WAVE PATTERNS WHEN THE CURRENT PACING WAS DELIVED ON THE TOP AREA OF $401 \times 50$. THE PATTERN OF $1200 \mathrm{~ms}$ IN FIGURE. 2 WAS USED AS THE START POINT AND CONSIDERED AS 0 ms HERE

FIGURE. 4 shows wave patterns when the current pacing was delivered on the whole tissue. As inspected, after being paced at $0 \mathrm{~ms}$, the membrane voltage of each myocyte was raised, leading to the potential at different region tend to be consistent at $5 \mathrm{~ms}$, thus suppressing the formation of new waveforms due to collision. So one can find that at $15 \mathrm{~ms}$ and $25 \mathrm{~ms}$, the turbulence was gradually weakened although it wasn't completely depressed. Following the subsequent pacings, the turbulence became less and less obvious and finally was eliminated at $625 \mathrm{~ms}$.



$0 \mathrm{~ms}$

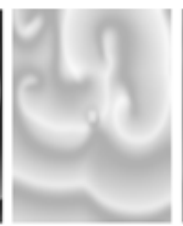

$5 \mathrm{~ms}$

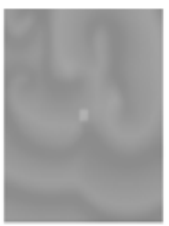

$15 \mathrm{~ms}$

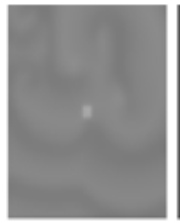

$25 \mathrm{~ms}$

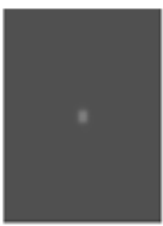

$625 \mathrm{~ms}$
FIGURE IV. ELECTRICAL WAVE PATTERNS WHEN THE CURRENT PACING WAS DELIVED ON THE WHOLE TISSUE. THE PATTERN OF $1200 \mathrm{~ms}$ IN FIGURE. 2 WAS USED AS THE START POINT AND CONSIDERED AS $0 \mathrm{~ms}$

\section{Effects of Current Pacing Together with Electrical Field}

Since the local current pacing had insignificant impact on the turbulence, then the current pacing in connection with electrical field was applied to the tissue. FIGURE. 5 shows wave patterns when the electrical field was delivered after 30 ms execution of current pacing on the top area of $401 \times 50$. As observed at $0 \mathrm{~ms}, 4 \mathrm{~ms}$ and $24 \mathrm{~ms}$, the current pacing partially depressed the turbulence of the top executed area. After application of the electrical field, the wave breakup at the top region was inhibited further at $48 \mathrm{~ms}$. Most of the broken waveforms were further inhibited at $72 \mathrm{~ms}$. Then with application of the subsequent periodic electrical fields, on can find that the turbulence was driven out of the tissue gradually from $100 \mathrm{~ms}$ to $168 \mathrm{~ms}$, and finally disappeared at $244 \mathrm{~ms}$. The results suggested that local current pacing together with the electrical field was able to eliminate the turbulence.
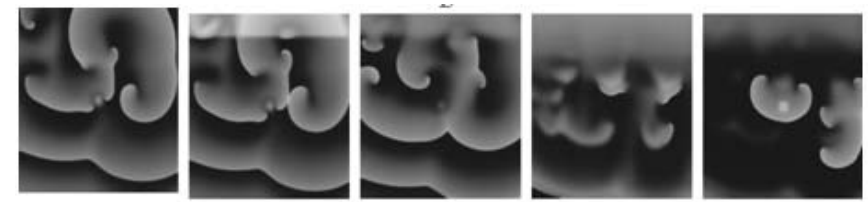

$$
0 \mathrm{~ms}
$$

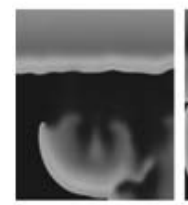

$4 \mathrm{~ms}$

$24 \mathrm{~ms}$

$48 \mathrm{~ms}$

$72 \mathrm{~ms}$

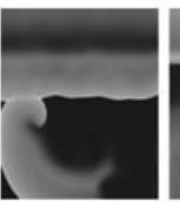

$120 \mathrm{~ms}$

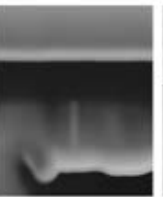

$-144 \mathrm{~ms}$

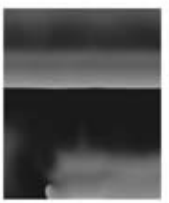

$168 \mathrm{~ms}$

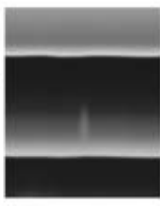

$244 \mathrm{~ms}$

FIGURE V. ELECTRICAL WAVE PATTERNS WHEN THE ELECTRICAL FIELD WAS DELIVED AFTER $30 \mathrm{~ms}$ EXECUTION OF CURRENT

PACING ON THE TOP AREA OF $401 \times 50$

FIGURE. 6 shows wave patterns when the electrical field was delivered after $30 \mathrm{~ms}$ execution of current pacing on the whole tissue. One can find that application of the current pacing greatly suppressed the turbulence $(0 \mathrm{~ms}$ to $28 \mathrm{~ms})$. After execution of the electrical field, the broken waves at the top area were further depressed at $36 \mathrm{~ms}$. Additionally, at 60 $\mathrm{ms}$ and $84 \mathrm{~ms}$ most of the myocytes had repolarized to the resting potential. Although new waves appeared again at 108 $\mathrm{ms}$, due to application of the subsequent electrical fields, the turbulence was completely eliminated at $240 \mathrm{~ms}$. Compared with the results in FIGURE. 4, the time to eliminate the turbulence was significantly reduced after the electrical field was executed.
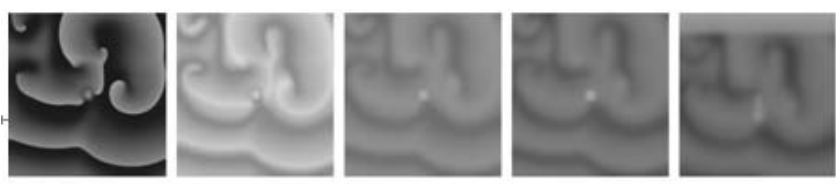

$0 \mathrm{~ms}$


$16 \mathrm{~ms}$
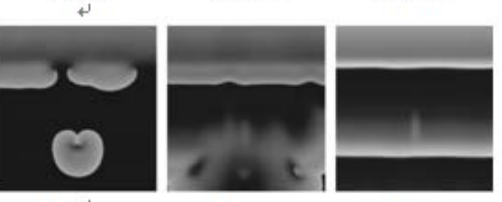

$60 \mathrm{~ms}$

$10 \stackrel{+}{8} \mathrm{~ms}$

$156 \mathrm{~ms}$ $240 \mathrm{~ms}$

FIGURE VI. ELECTRICAL WAVE PATTERNS WHEN THE ELECTRICAL FIELD WAS DELIVED AFTER $30 \mathrm{~ms}$ EXECUTION OF CURRENT PACING ON THE WHOLE TISSUE.

\section{CONCLUSIONS}

Local current pacing has no significant effects on the turbulence induced by membrane potential oscillations. Current pacing on the whole tissue can suppress wave breakup on the developed local pathological tissue, but it needs to take a long time. The method of current pacing together with electrical field is able to promote the process to suppress the wave breakup, suggesting its efficacy in elimination of the turbulence induced by voltage oscillations in hearts. 


\section{ACKNOWLEDGMENT}

This work is supported by the National Natural Science Foundation of China (Nos. 81271661, 30870659), the Health Foundation of Shaanxi province in China (08D23), the Scientific Research Foundation for the Returned Overseas Chinese Scholars, State Education Ministry (SRF for ROCS), and the Fundamental Research Funds for the Central Universities.

\section{REFERENCES}

[1] D. X. Tran, D. Sato, and A. Yochelis, "Bifurcation and chaos in a mode of cardiac early after- depolarizations," Phys. Rev. Lett., vol. 102, pp. 258103 1-4, June 2009

[2] Z. Cao, H. Zhang, F. Xie and G. Hu, "Controlling turbulence in excitable media by applying boundary periodic pacing and gradient force," Europhys. Lett., vol. 75, pp. 875-881, September 2006.

[3] Z. Cao, H. Zhang, F. Xie and G. Hu, "Controlling turbulence in excitable media by applying boundary periodic pacing and gradient force," Europhys. Lett., vol. 75, pp. 875-881, September 2006.
[4] C. M. Ambrosi, C. M. Ripplinger, and I. R. Efimov, "Termination of sustained atrial flutter and fibrillation using low-voltage multiple-shock therapy," Heart rhythm, vol. 8, pp. 101-108, January 2011.

[5] S. Luther, F. H. Fenton, B. G. Kornreich, and A. Squires, "Low-energy control of electrical turbulence in the heart," Nature, vol. 475, pp. 235 239, July 2012.

[6] Z. L. Qu, L. H. Xie, and R. Olcese, "Early afterdepolarizations in cardiac myocytes: beyond reduced repolarization reserve," Cardiovasc. Res., vol 99 , pp. 6-15, July 2013

[7] N. Trayanova, "Defibrillation of the heart: insights into mechanisms from modelling studies," Exp. Physiol., vol. 91, pp. 323-337, March 2006.

[8] C. H. Luo, and Y. Rudy, "A model of the ventricular cardiac action potential: Depolarization, repolarization, and their interaction," Circ. Res., vol. 68, pp. 1501-1526, May 1991.

[9] H. Zhang, Z. Yang, L. Yang, and Shu Kong, "Effects of high extracellular $\mathrm{K}+$ in atrium on pacemaker activity of sinoatrial node, "Pak. J. Pharm. Sci., vol. 27, pp. 2041-2046, November 2014.

[10] Y. L. Kuang, and G. N. Tang, "Suppression of spiral waves and spatiotemporal chaos in cardiac tissue," Acta Phys. Sin., vol. 61, pp. $1005041-8$, October 2012 